\title{
Amorphus globosus foetuses in Polish Holstein cattle: anatomical, histological, and genetic studies
}

\author{
Marek Gehrke ${ }^{1}$, Beata Blaszak ${ }^{2}$, Monika Stachowiak $^{3}$, \\ Izabela Szczerbal $^{3}$, Barbara Stefańska ${ }^{4}$, Jędrzej M. Jaśkowski ${ }^{1}$, \\ Włodzimierz Nowak ${ }^{4}$, Marek Switoński ${ }^{3}$ \\ ${ }^{1}$ Centre for Veterinary Sciences at the Nicolaus Copernicus University, 87-100 Torun, Poland \\ ${ }^{2}$ Department of Tumour Pathology, Greater Poland Cancer Centre, 61-866 Poznań, Poland \\ ${ }^{3}$ Department of Genetics and Animal Breeding, ${ }^{4}$ Department of Animal Nutrition and Feed Management, \\ Faculty of Veterinary Medicine and Animal Sciences, \\ Poznań University of Life Sciences, 60-637 Poznań, Poland \\ mgehrke@umk.pl
}

Received: August 15, 2018 Accepted: August 7, 2019

\begin{abstract}
Introduction: A comprehensive description is presented of four novel cases of amorphus globosus (ag) foetuses originating from multiple pregnancies of Polish Holstein cows. Material and Methods: Four amorphic foetuses were delivered by three cows. Tissue samples were collected during autopsy, embedded in paraffin, sectioned, and stained with haematoxylin and eosin. Genomic DNA was isolated from tissue samples of abnormal foetuses and from blood leukocytes of their healthy siblings. PCR reactions were used to reveal the presence of Y-linked genes (SRY and AMELY) and an X-linked gene (AMELX). Results: All foetuses were classified to the group holoacardius amorphous (anideus). Molecular analysis clearly showed that at 17 microsatellite loci, the studied amorphous foetuses had identical genotypes to the viable co-twins. Conclusion: Foetuses had monozygotic origin. Histological analysis showed a low level of development of tissues of meso- and ectodermal origin, as well as features of degrading patterns.
\end{abstract}

Keywords: cattle, foetuses, amorphus globosus, histology, monozygotic pregnancy.

\section{Introduction}

Amorphus globosus (ag) foetuses are rarely reported in domestic animals, but the majority of recently documented cases were found in cattle, as well as in goats, sheep, and buffaloes $(1,5,7-10,12-14,16$, 18-20, 22-25). The customary name amorphus globosus describes the shape of the foetus and the absence of clear differentiation of phenotypic body parts. The lack of an independent circulatory system expressed in the Latin name acardius amorphus is a characteristic feature of the defect. The gross appearance of the teras is characterised by a round or spherical shape, generally without differentiated body parts, and is covered with hairy skin to a varying degree. The inner mass consists of tissue, some mesodermal (connective, muscle, adipose and adenoid, and cartilaginous and/or bone) and some ectodermal
$(1,5,13,14,22)$. They do not form any anatomical structures (or functional organs), but an exception to this has been noted, which included the presence of primordial germs of extremities (1).

Cases of amorphous foetuses in animals suggest that they usually do not occur by themselves but nearly always coexist with a living or dead co-twin or with comultiples, which do not show any phenotypic malformations. Terata were usually found in cases of dystocia which were a result of incorrect foetal position. Normal foetuses and their coexisting $a g$ foetus may be of the same or opposite sexes $(1,10,24,25)$. However, it has been suggested that the female sex is predominant among the properly developed foetuses $(14,17-19,22)$. There are also reports of the presence of $\mathrm{XX} / \mathrm{XY}$ chimerisms and other chromosomal abnormalities in ag co-twins which originated from the transfer of two embryos $(16,19)$. 
Since the origin of ag foetuses is obscure, we undertook a comprehensive description, including morphological, histological, and genetic analysis of four novel ag cases which originated from multiple pregnancies of three Polish Holstein cows.

\section{Material and Methods}

Incidences. Four amorphous foetuses were delivered by three cows:

Cow A: a three-year-old 80\% Holstein Friesian (HF) after the second calving. This cow gave birth to a live bull-calf (Am) weighing $33 \mathrm{~kg}$ and an $a g$ teras (A1) with a spherical shape of $12.0 \times 12.0 \mathrm{~cm}$, weighing $533 \mathrm{~g}$ and with well-developed skin thinly covering the entire surface. Unpigmented skin occupied approximately $30 \%$ of the total area and was covered with long white thin hair (approximately $1.5 \mathrm{~cm}$ in length) in contrast to the pigmented skin area. A strip of $5 \mathrm{~cm}$ maximal width which narrowed at the ends closer to the umbilical cord divided the pigmented skin surface area into two unsymmetrical parts. The preserved thin umbilical cord section had a thickness of approximately $1 \mathrm{~cm}$ and a length of approximately $25 \mathrm{~cm}$. The calf was delivered after 272 days of gestation and the expulsion of the placenta occurred spontaneously.

Cow B: a five-year-old HF after the third calving. Parturition produced two apparently normal dead bulls, without any signs of developmental disorders, and an elongated oval shaped ag (B1) measuring $15.3 \times 8.5 \mathrm{~cm}$, weighing $390 \mathrm{~g}$, and covered with thin skin. Most of its surface was pigment-free $(5 \%$ of the skin had black pigment) with scant thin white hair strands. The calves were delivered after 272 days of gestation but required obstetric intervention due to obstruction caused by impaction of both foetuses. The postnatal examination revealed the presence of a spherical malformed comultiple which was removed from the uterine cavity along with a part of the placenta. The retained placenta was noted after delivery.

Cow $\mathrm{C}$ : a four-year-old HF after the third calving. The animal delivered two live calves (a heifer (C-f) of $32 \mathrm{~kg}$ and a bull (C-m) of $33 \mathrm{~kg}$ ) along with two $\mathrm{ag}$ of dissimilar sizes and shapes. The larger (C1) was spherical, measuring $15.7 \times 15.0 \mathrm{~cm}$, weighing $769 \mathrm{~g}$ and with well-developed skin covered with thick, black hair (approximately $1.5 \mathrm{~cm}$ long) covering approximately $95 \%$ of its surface. An area of unpigmented skin of approximately $5 \mathrm{~cm}^{2}$ was found peripherally from the umbilical cord and a smaller area located right around the umbilical cord was covered with sparser and slightly longer white hair. On the surface, there were no natural orifices or primordial body parts that would suggest its anterior and posterior (cranial and caudal) ends. The preserved portion of the umbilical cord had a thickness of approximately $2.5 \mathrm{~cm}$ and a length of approximately $30 \mathrm{~cm}$. There were no cotyledons detected. The second amorphous foetus (C2) was made up of two spherical structures with dimensions of $8.7 \times 8.5 \mathrm{~cm}$ and $5.1 \times 3.8 \mathrm{~cm}$ and a combined weight of $344 \mathrm{~g}$; they were joined by a narrower section of tissue with a width of $3.8 \mathrm{~cm}$. Both were covered with well-developed skin densely covered with hair and pigmented over most of their surface. The intact portion of the umbilical cord had a diameter of approximately $5.5 \mathrm{~cm}$ and a length of $15 \mathrm{~cm}$; in the part still in contact with the foetal mass, there was a fatty body measuring $5.8 \times 4.4 \mathrm{~cm}$ and weighing $84.5 \mathrm{~g}$. Two cotyledons were located more peripherally. Delivery was aided with the use of a calf puller after 273 days of gestation. The examination of the uterine cavity confirmed the existence of additional amorphous structures, which were removed mechanically. A retained placenta was noted in the course of postnatal care.

Histology. Tissue samples were collected during autopsy. They represented a cross-section of three layers, including the skin and the tissues located deeper, as far as to the central zone of the amorphous foetus. Samples were fixed in $10 \%$ buffered neutral formalin. The tissue was embedded in paraffin, sectioned at $5 \mu \mathrm{m}$, and stained with haematoxylin and eosin (HE).

Cytogenetic and molecular genetic studies. Chromosome preparations were obtained from a shortterm lymphocyte culture. Briefly, heparinised blood was cultured in RPMI 1640 medium, supplemented with foetal calf serum (15\%), an antibiotic-antimycotic mixture (1\%), and phytohaemagglutinin for $72 \mathrm{~h}$ at $37^{\circ} \mathrm{C}$. After colcemid treatment, a standard harvesting procedure including hypotonic and fixative steps was applied. Chromosome slides were conventionally stained with Giemsa solution and analysed under an E600 Eclipse microscope (Nikon, Japan). Bovine sex chromosomes were identified based on their bi-armed morphology, i.e. a large submetacentric $\mathrm{X}$ chromosome and a small metacentric Y chromosome. For each individual 50 metaphase spreads were evaluated.

Genomic DNA was isolated from tissue samples of the abnormal foetuses (A1, B1, C1, and $\mathrm{C} 2$ ) using a Genomic Mini kit (A\&A Biotechnology, Poland) and from blood leukocytes of their healthy siblings (cases A and C) using a Blood Mini kit (A\&A Biotechnology). PCR reactions were used to reveal the presence of Y-linked genes (SRY and AMELY) and an X-linked gene (AMELX). To detect the $S R Y$ gene, a PCR reaction was performed with primers (5'-AAGAACAACTTAT GAATAGCACCA-3' and 5'-TTAAGTCGCAGGTGA AACTGT-3') resulting in an $851 \mathrm{bp}$ amplicon. To detect the $A M E L X$ and $A M E L Y$ genes the PCR reaction was carried out with primers (5'-CAGCCAAACCTCC CTCTGC-3' and 5'-CCCGCTTGGTCTTGTCTGT TGC-3') amplifying a $280 \mathrm{bp}$ fragment of the AMELX gene and a $217 \mathrm{bp}$ fragment of the AMELY gene. The PCR conditions were initial denaturation at $94^{\circ} \mathrm{C}$ for 
5 min, followed by 35 cycles of denaturation at $94^{\circ} \mathrm{C}$ for $30 \mathrm{~s}$, primer annealing at $60^{\circ} \mathrm{C}$ or $64^{\circ} \mathrm{C}$ for $30 \mathrm{~s}$ (for the $S R Y$ and $A M E L X / A M E L Y$ genes, respectively), primer elongation at $72^{\circ} \mathrm{C}$ for $1 \mathrm{~min}$, and the final elongation at $72^{\circ} \mathrm{C}$ for $5 \mathrm{~min}$. The resulting PCR fragments were visualised using agarose gel electrophoresis. DNA profiles were established for the abnormal foetuses (A1, C1, and C2) and their healthy siblings (Am, $\mathrm{Cm}$, and $\mathrm{Cf}$ ) using 17 microsatellite markers (TGLA227, BM2113, ETH10, SPS115, SPS113, RM067, TGLA126, TGLA122, INRA23, BM1818, ETH3, ETH225, BM1824, CSRM60, MGTG4B, CSSM66, and ILSTS006) by Dr Van Haeringen Laboratory (VHL Genetics, the Netherlands).

\section{Results}

All ag foetuses were classified in the group holoacardius amorphus (anideus). Macroscopic comparisons focused attention on four main differences between the studied ag: size/weight, shape, hair density, and differences in the appearance of the umbilical cord stump. The biggest $a g$ were observed in the cases of the double and quadruple pregnancies, in which the amorphous forms came from homozygous pregnancies, as confirmed by genetic testing. The case of the birth of two ag was identified as a homozygous triple pregnancy (Table 1), whereby both amorphous foetuses differed substantially in shape, size, and weight. Although similar in size and shape, the large, spherical amorphous forms had different hair densities (Figs 1 and 3). The lowest hair density was observed in B1 (Fig 2), in which hair was only residual, and the highest in $\mathrm{C} 1$ and $\mathrm{C} 2$ (Figs 3 and 4). In the case of $\mathrm{C} 2$, the histological examination revealed a further higher density of hair in the pigmented skin area. Lower hair density was associated with its more balanced and advanced development (fewer hair follicles at various stages of development, and well-developed structure of the hair and follicles).

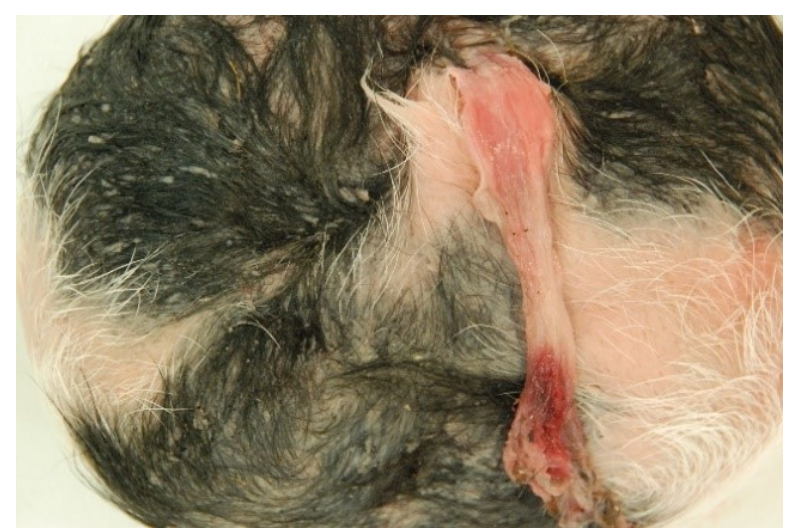

Fig. 1. Amorphus globosus A1 of cow A
The appearance of the intact fragments of the umbilical cord remnants varied (Figs 1-4). The thinnest stump was found in A1, while the longest were in B1 and $\mathrm{C} 1$. The umbilical cord stump of $\mathrm{C} 2$ was short, but in the immediate vicinity of the amorphous mass outside the fatty body, it contained two cotyledons.

Dominant in A1 were a large variety of early forms of hair development (Fig. 5). Asynchronicity of their development and the presence of the same forms of development at different distances from the epidermis was observed. B1 was an isolated case, where very thin unpigmented hair dominated. Circular cross-sections of numerous channels and hair sheaths in the layers abundant in keratin, i.e. the epidermis and dermis, indicate more horizontal rather than perpendicular hair development.

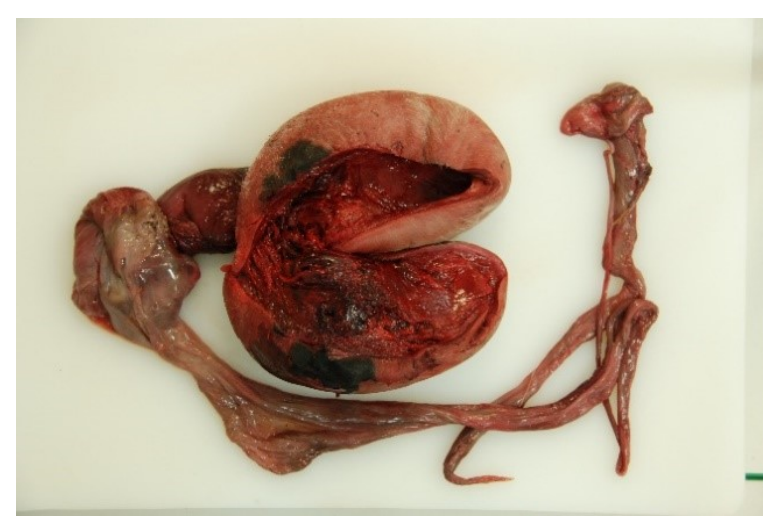

Fig. 2. Amorphus globosus B1 of cow B

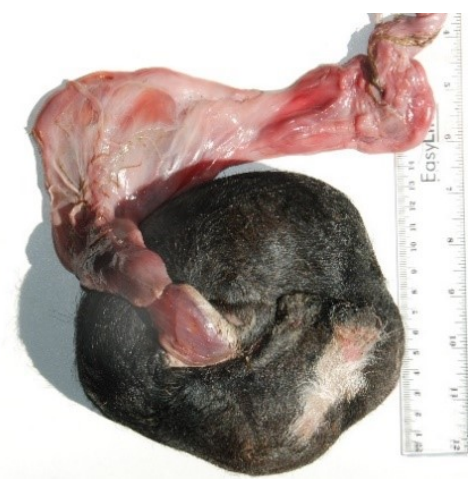

Fig. 3. Amorphus globosus $\mathrm{C} 1$ of cow $\mathrm{C}$

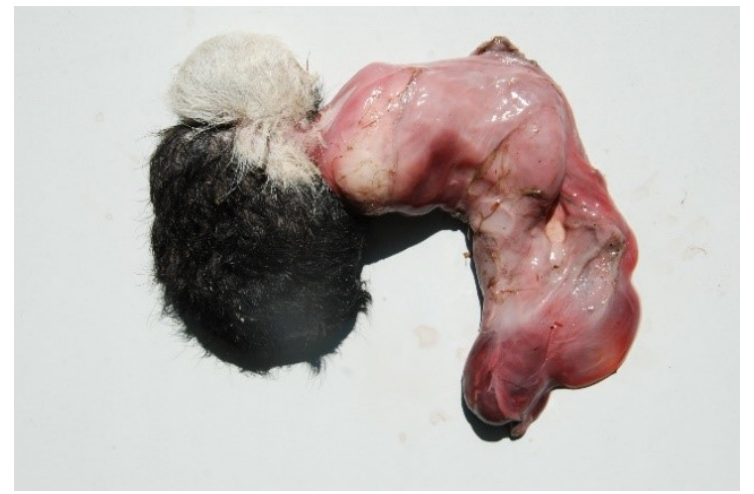

Fig. 4. Amorphus globosus $\mathrm{C} 2$ of cow $\mathrm{C}$ 
On the border between the layers of keratin, separated from the deeper tissue, there were either no cells observed or they occurred singly (an epidermal cell layer was lacking). Moreover, the tissues lying deeper were hypocellular, with the exception of regions in the immediate vicinity of the very early forms of hair development. A similar structure was characterised by a wall cavity located in the amorphous mass (Fig. 6), in which elements of the structure of the hair occurred less frequently. In the separating layer of keratin and deeper tissues, cells with the characteristics of kernel defragmentation were found.

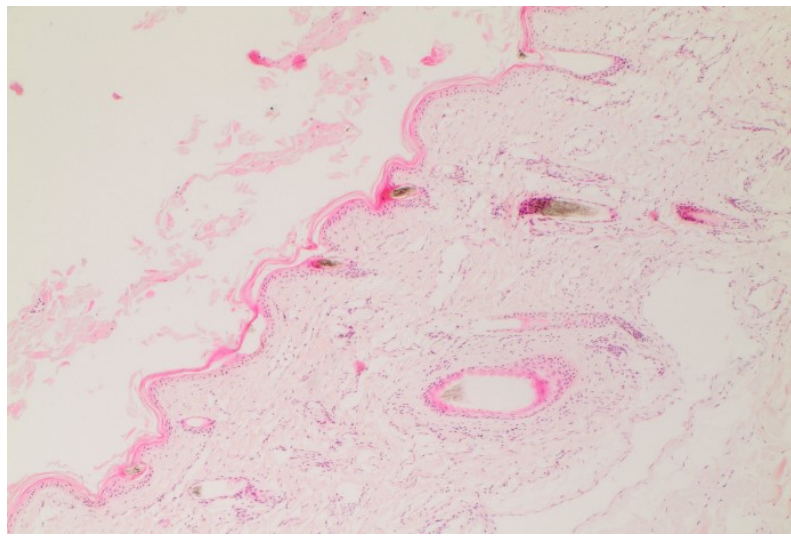

Fig. 5. Skin of A1. The area of black hair, epidermal cells with a layer of keratin, the early developmental stages of hair, and segmental separation of the keratin layer $(4 \times, \mathrm{HE})$

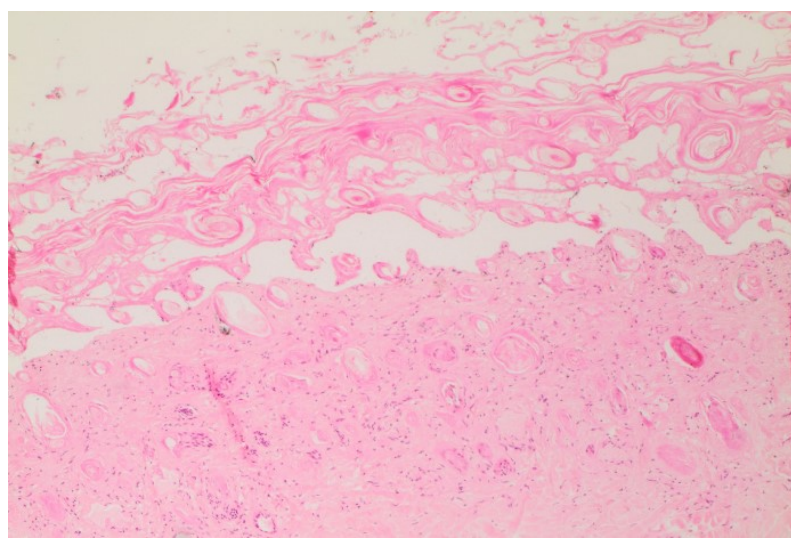

Fig. 6. Wall of internal cavity of B1. The layer of keratin with a few cells getting separated, horizontally running sheaths of hair without cellular elements, absence of cell layers in the epidermis, the dermis with a few cells indicating defragmentation of nuclei, and early stages of hair development $(4 \times, \mathrm{HE})$

The histopathological examination of selected areas of the parenchyma of the amorphous foetuses revealed tissues of meso- and ectodermal origin. In all cases, fatty, mesenchymal tissue with varying density of cells and matrix as well as muscle dominated (Figs 7 and 8). Large fluid passages and vessels of various wall organisations and clusters of lymphoid tissue occurred in the mass of the parenchyma (Fig. 8). Figures 9 and 10 illustrate irregular spaces with features of epithelial lining as well as the chondral elements similar in structure to long bones observed in $\mathrm{C} 2$. In the parenchyma of B1 there was an oval sponge-like bone mass with approximate dimensions of $3.0 \times 2.5 \times$ $1.5 \mathrm{~cm}$ (no image) and in adjacent parenchyma areas corresponding to skeletal muscle.

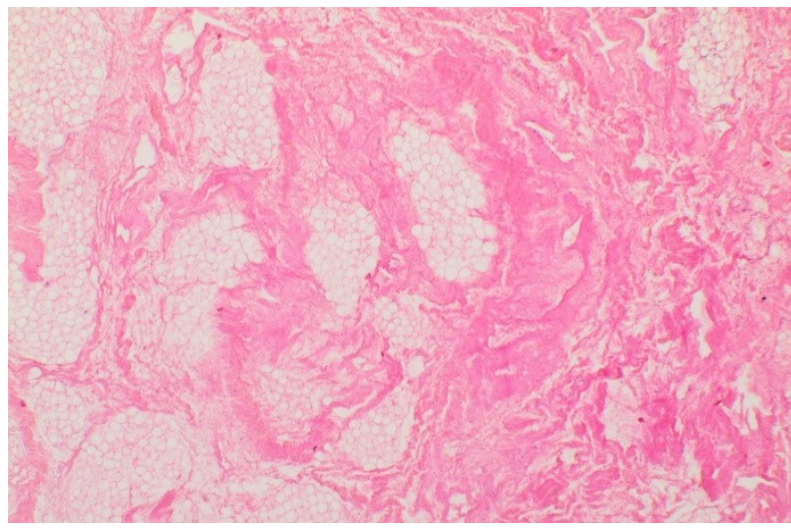

Fig. 7. Mesenchymal and fat tissue of B1. A dense extracellular matrix devoid of cellular elements $(2 \times, \mathrm{HE})$

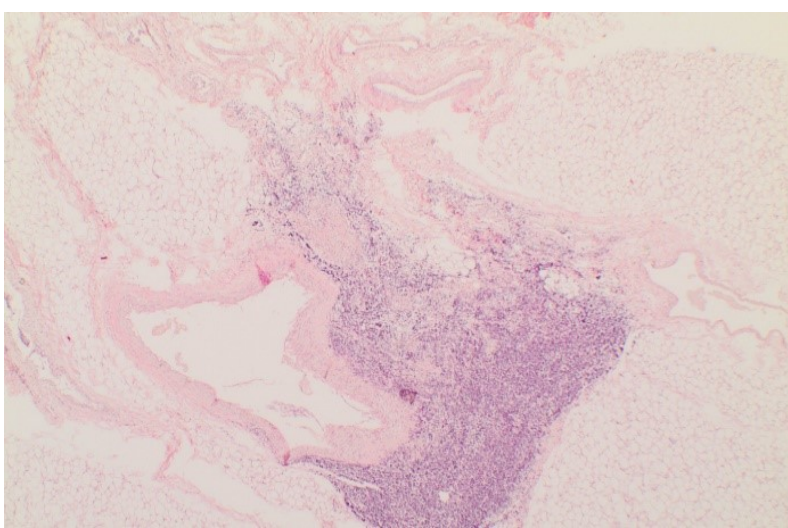

Fig. 8. Connective tissue of $\mathrm{C} 2$ with clusters of fat, vessels, and lymphatic tissue. Structural diversity in the vascular walls (first stage of endothelial organisation) $(2 \times, \mathrm{HE})$

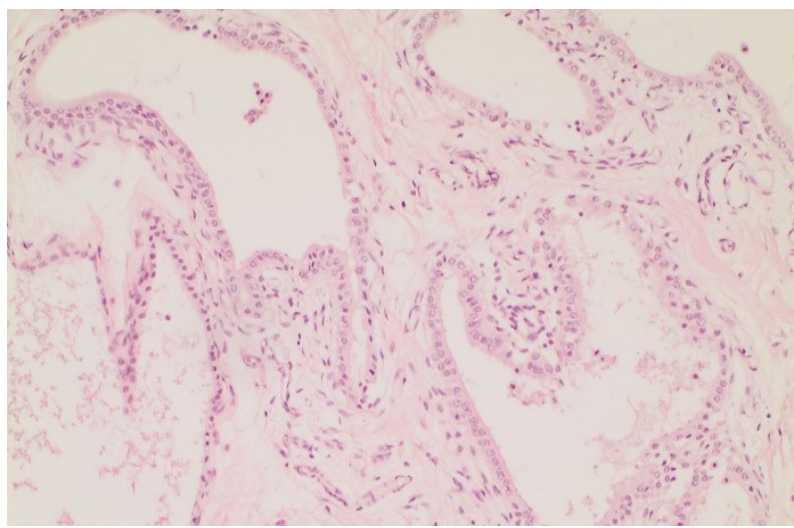

Fig. 9. In $\mathrm{C} 2$, the free spaces with the features of epithelial lining of $(10 \times, \mathrm{HE})$ 


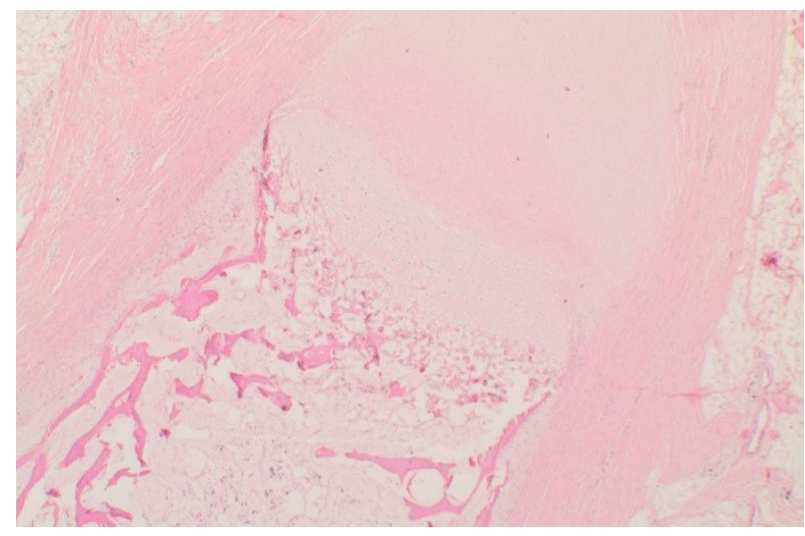

Fig. 10. Buds of early bone structure of $\mathrm{C} 2(2 \times, \mathrm{HE})$

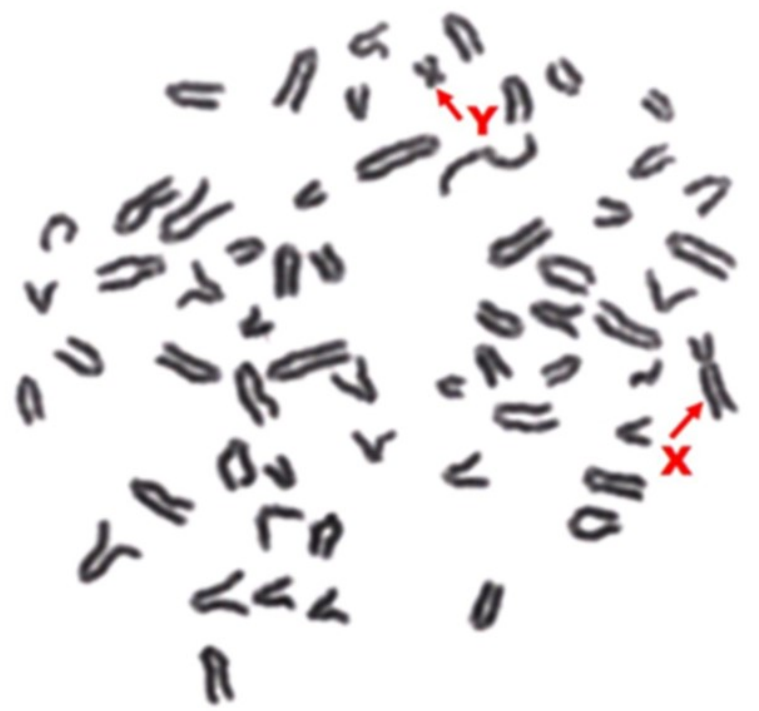

Fig. 11. Giemsa-stained metaphase spreads of the viable sibling A-m $(60, \mathrm{XY})$

The chromosome complement was analysed in the normal siblings of amorphic foetuses (A-m, C-m, and $\mathrm{C}-\mathrm{f}$ ) in order to determine their sex chromosomes and search for leukocyte chimerism (XX/XY), which is very common in heterosexual twins. It was found that in all viable calves, only one cell line was identified and the sex chromosome complement was as follows:
A-m (60, XY), C-m (60, XY), and C-f (60, XX) (Figs 11 and 12 , Table 1$)$.

A comparative study of microsatellite polymorphism of the amorphous foetuses (A1, C1, and $\mathrm{C} 2$ ) and their normal siblings (A-m, C-m, and C-f) showed that they derived from the same zygotes. Amorphous foetus A1 and its normal sibling had the same genotype at 17 microsatellite loci and Y-linked (SRY and AMELY) and X-linked (AMELX) genes (Figs 13 and 15). The $\mathrm{C} 1$ and $\mathrm{C} 2$ amorphous foetuses had the same genotype at the studied microsatellite loci as their normal female sibling (C-f). Moreover, in both foetuses only the AMELX gene was detected (Figs 14 and 16). In the foetus B1 two Y-linked (SRY and AMELY) and an X-linked $(A M E L X)$ gene were found. Unfortunately, molecular analysis of the two stillborn male full siblings was not possible. The results for cow A's product of conception and offspring showed that amorphous foetus $\mathrm{A} 1$ and normal male calf (A-m) originated from the same zygote. Similarly, the C1 and $\mathrm{C} 2$ amorphous foetuses and the normal female calf (C-f) also originated from the same zygote.

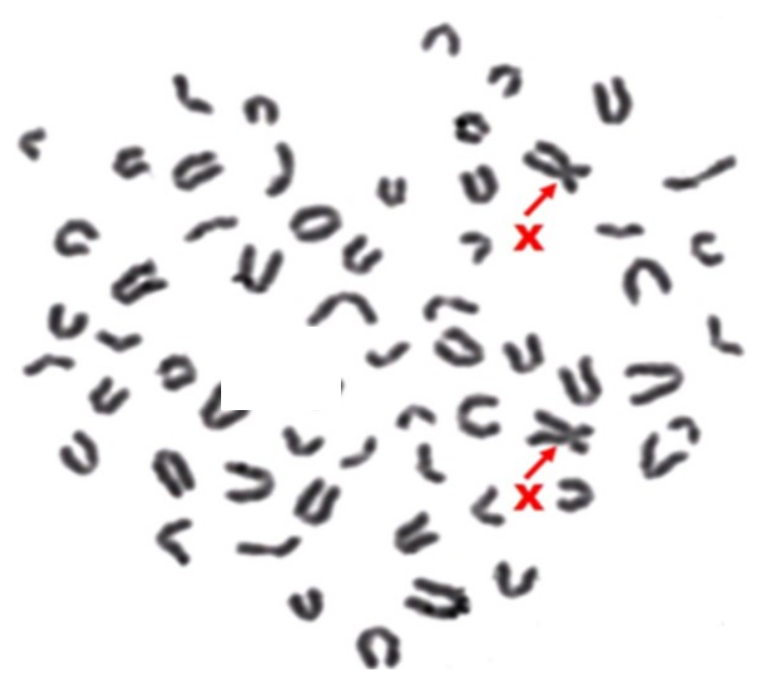

Fig. 12. Giemsa-stained metaphase spreads of the viable sibling $\mathrm{C}-\mathrm{f}$ $(60, \mathrm{XX})$

Table 1. Genetic analysis of the amorphic foetuses and their full siblings

\begin{tabular}{|c|c|c|c|c|c|c|}
\hline \multirow{2}{*}{ Multiplets } & \multirow{2}{*}{ Individuals } & \multirow{2}{*}{ Karyotype } & \multicolumn{3}{|c|}{ Genes } & \multirow{2}{*}{ STR (17 loci) } \\
\hline & & & $S R Y$ & $A M E L X$ & $A M E L Y$ & \\
\hline \multirow{2}{*}{ A } & Normal male $(\mathrm{A}-\mathrm{m})$ & $60, X Y$ & + & + & + & The same genotype as A1 \\
\hline & $A g-(\mathrm{A} 1)$ & & + & + & + & The same genotype as co-twin \\
\hline \multirow{3}{*}{ B } & Stillborn male & na* & na & na & na & na \\
\hline & Stillborn male & na & na & na & na & na \\
\hline & $A g-(\mathrm{B} 1)$ & & + & + & + & na \\
\hline \multirow{4}{*}{$\mathrm{C}$} & Normal male (C-m) & $60, \mathrm{XY}$ & + & + & + & Genotype different from $\mathrm{C}-\mathrm{f}, \mathrm{C} 1$, and $\mathrm{C} 2$ \\
\hline & Normal female $(\mathrm{C}-\mathrm{f})$ & $60, \mathrm{XX}$ & - & + & - & The same genotype as $\mathrm{C} 1$ and $\mathrm{C} 2$ \\
\hline & $A g-(\mathrm{C} 1)$ & & - & + & - & The same genotype as C-f and C2 \\
\hline & $A g-(\mathrm{C} 2)$ & & - & + & - & The same genotype as C-f and C1 \\
\hline
\end{tabular}

*na-not analysed 


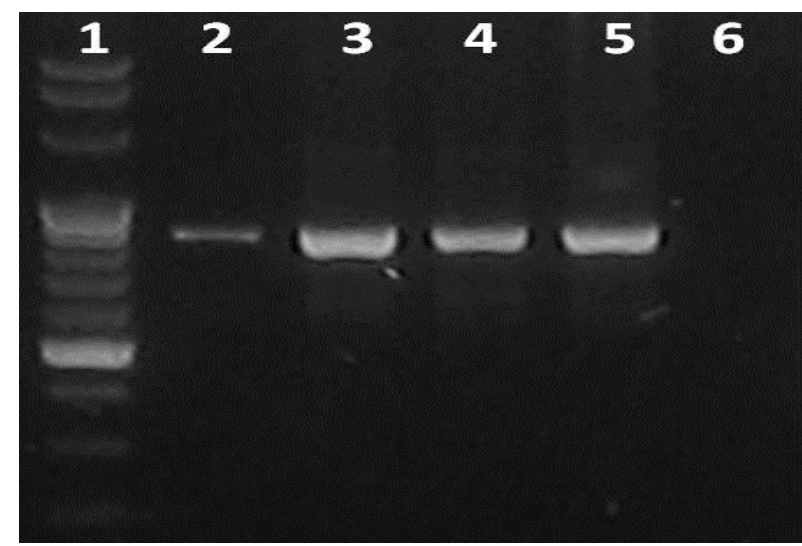

Fig. 13. Electrophoresis of PCR products of the $S R Y$ gene $(851 \mathrm{bp})$ of A1, B1, and the healthy brother of A1. Lanes: 1 - molecular weight marker; 2 - abnormal foetus B1; 3 - abnormal foetus A1; 4 - healthy brother of abnormal foetus A1; 5 - reference male; 6 - reference female

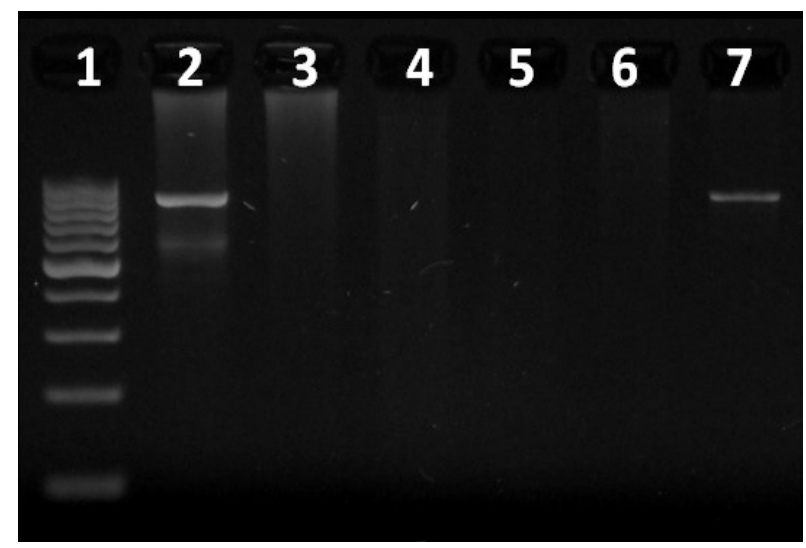

Fig. 14. Electrophoresis of PCR products of the $S R Y$ gene $(851 \mathrm{bp})$ of $\mathrm{C} 1, \mathrm{C} 2$, healthy male, and female co-multiples. Lanes: 1 - molecular weight marker; 2 - healthy brother; 3 - healthy sister; 4 - abnormal foetus $\mathrm{C} 1 ; 5$ - abnormal foetus $\mathrm{C} 2 ; 6$ - reference female; 7 - reference male

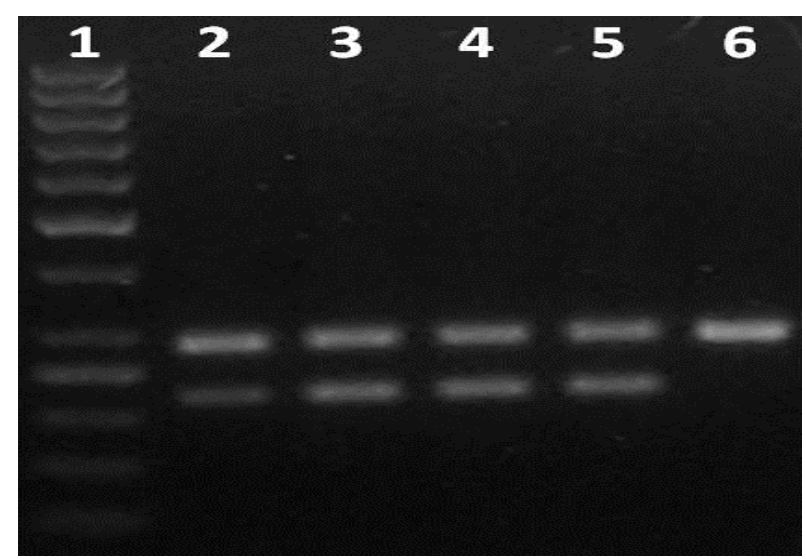

Fig. 15. Electrophoresis of PCR products for AMELX and AMELY genes of A1, B1, and healthy brother of A1. Two bands ( $280 \mathrm{bp}$ and $217 \mathrm{bp}$ ) are visible in males and a single band (280 bp) in the female. Lanes: 1 - molecular weight marker; 2 - abnormal foetus B1; 3 - abnormal foetus A1; 4 - healthy brother of abnormal foetus A1; 5 - reference male; 6 - reference female

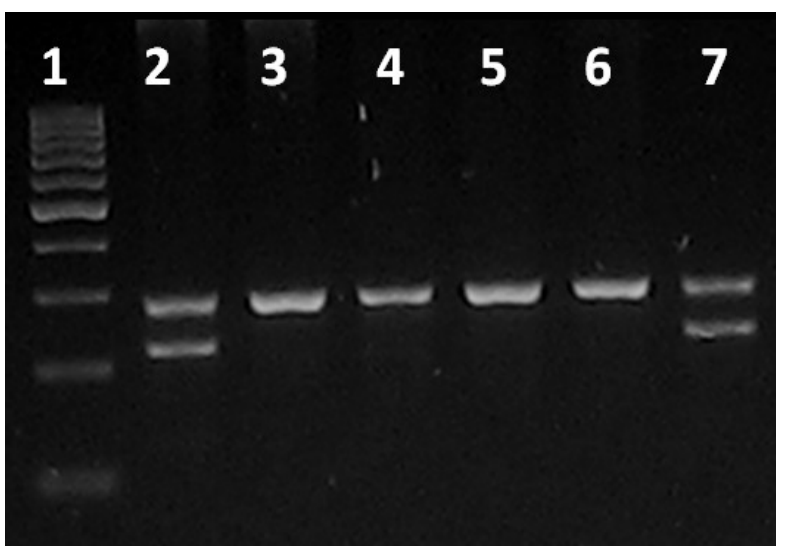

Fig. 16. Electrophoresis of PCR products for $A M E L X$ and $A M E L Y$ genes of $\mathrm{C} 1, \mathrm{C} 2$, and healthy male and female co-multiples. Two bands (280 bp and $217 \mathrm{bp}$ ) are visible in males and a single band (280 bp) in females. Lanes: 1 - molecular weight marker; 2 - healthy brother; 3 - healthy sister; 4 - abnormal foetus $\mathrm{C} 1$; 5 - abnormal foetus $\mathrm{C} 2 ; 6$ - reference female; 7 - reference male

\section{Discussion}

Most cases of ag described in the literature as well as cases from personal experience were discovered at the point of obstetric assistance or during medical intervention after a retained placenta had come to notice. All the deliveries took place after the normal duration of gestation. An amorphous foetus has also been documented in a cow that died in the eighth month of a hexafoetal pregnancy (10). Due to its low weight the parasitical foetus is rarely the cause of lower birth weight of the co-multiples. This can be confirmed by the similar body weight of the two live newborns, one of which was a homozygous co-multiple of the two amorphous foetuses (case C). In the rest of the cases of pregnancy with ag described in this paper, the welldeveloped embryos had a mass within the range of normal values.

Our observations did not confirm the opinion that the female sex is more common among co-twins of $a g$ (22). From our case study, it was the male sex that predominated among the animals without phenotypic defects, while the sex of ag varied determined on the basis of genetic tests.

Records of congenital disorders indicate that occurrences of $a g$ in animals are quite rare (4). In humans, their incidence is estimated at 1 per 35,000 pregnancies or $1 \%$ of monozygotic twin pregnancies, pointing to the possibility of coexistence in multiple pregnancies $(2,3,15)$. Amorphous foetuses have living tissue at the point of birth, hence in the absence of the heart, the supply of oxygen and nutrients requires communication with the vascular system of a co-twin. Blood flow in $a g$ in homozygous pregnancies is possible thanks to collateral circulation and/or arterioarterial anastomoses of the chorion, whereas in heterozygous pregnancies this theoretically only takes place through anastomoses. Thus, the degree of blood 
supply can be the result of various pathological developmental variants of the vascular system.

The causes of acardia include insufficient embryonic mesoderm, anastomoses between the vessels of the umbilical cord, and disturbances in the return flow of blood from the placenta to the foetus (5). In the present day, a twin reversed arterial perfusion is indicated as the main cause of the defect (11). It is a rare complication of monochorionic pregnancy that involves countercurrent flow of deoxygenated blood from the umbilical cord arteries of the foetus through its branch connected to the umbilical artery of the twin with acardia and its return along the umbilical cord vein back to the placenta. Such advanced defects in the construction of vessels in the ruminant placenta have not been confirmed.

Developmental disorders arising as a result of TRAP are called disruption or breakage and they involve lesions in the preexisting tissue structures, which had been developing properly up to a certain point. Amorphous foetuses of ruminants show an extremely low degree of tissue organisation $(1,13$, 14). However, during histopathological tests, certain features were found to confirm the theory of disruption. In all cases, the keratin layer tended to be separate from the deeper underlying tissue. Its presence in the skin was observed in all cases, but in some of them it was expanded and occurred despite the absence of or very sparse presence of skin cells. In B1, similarly to skin, the cavity lining contained developed hair, however, there were no cellular elements in the hair sheaths. Also the buds of roots and hair canals were hypocellular. Beneath the keratin layer, decay of cell nuclei was observed. There were large areas of the matrix of connective tissue with few cells found in the parenchyma. These features were most clearly marked in the case of B1, deriving from a triple pregnancy which resulted in the delivery of two dead coexisting foetuses. In $\mathrm{C} 2$ free spaces indicated only partial epithelialisation of the lining.

In the literature there is a lack of conclusive evidence on the possibility of the development of an amorphous foetus in a multiple pregnancy of mixed sexes. However, it does describe two cases of twin pregnancies with $a g$, which were preceded by double ovulation confirmed by the presence of two corpora lutea on the ovaries at the time of birth, and it also reports the occurrence of chimerism in female co-twins as well as a case of an amorphous foetus delivered after the transfer of two embryos after in vitro fertilisation $(16,19,22,25)$.

Our molecular analysis clearly showed that the studied amorphous foetuses had genotypes at 17 microsatellite loci identical to those of the viable co-twins, thus, their origin was monozygotic. Interestingly, a dizygotic origin of ag was recently reported by Weber et al. (25), who genotyped the samples.
The degree of tissue organisation of $a g$ was partly linked to the appearance of the surviving fragments of the umbilical cord. A very thin or long umbilical cord stump was observed in the $a g$ with the lowest degree of tissue differentiation $(\mathrm{A} 1 / \mathrm{C} 1)$, while in the case of the umbilical cord with cotyledons, even though the amorphous foetus was the smallest, it revealed the highest diversity of tissues (C2). This indicates that the size of the ag does not reflect the progress of the development of tissue. Only B1 went counter to the umbilical cord and tissue differentiation relationship, because despite a long thick umbilical cord, bone tissue indicated a more advanced development of mesodermal derivatives in the foetal mass. In this case, the presence of the cavity in the amorphous mass and the similarity of the histological structure of its wall with the skin indicate the disordered migration of embryonic primordia of the ectoderm. The nuclear disintegration in cells in the lining of the cavity and the lack of cellular elements in the immediate vicinity of exfoliating keratin layers on the surface of B1 (no skin) indicate degenerative regressive processes.

Sometimes co-twins of amorphous foetuses are born dead $(1,25)$. They usually die as a result of becoming stuck in the reproductive tract, prolonging the delivery and hypoxia. The available literature lacks data on the impact of $a g$ in animals on growth and survival of co-multiples. The heart of the foetus with no defect bears the functional load resulting from the need to supply blood to both itself and the $a g$. Hypoxia of tissues may be the reason for increased neovascularisation of amorphic foetuses (6). A decrease in vascular resistance resulting from the need to maintain blood pressure and oxygenation in the parasitic foetus systematically increases the workload on the heart of the "pumping" foetus. In human monochorionic foetuses from twin pregnancies with $a g$ we can observe congestive heart failure. It may result in intrauterine growth retardation, foetal death, stillbirths, and increased mortality during the post-parturient period. The impossibility of performing an autopsy on the stillborn foetuses of cow B and only one description of the changes that occur following the autopsy of a stillborn heifer in the literature make it impossible to entertain the coexistence described in cattle (25).

Our investigation proved that the studied foetuses originated from monozygotic twins in which the cotwins were normally developed. The histological analysis showed a low level of development of tissues of meso- and ectodermal origin, as well as features of degrading patterns.

Conflict of Interests Statement: The authors declare that there is no conflict of interests regarding the publication of this article.

Financial Disclosure Statement: This research was supported by the Centre for Veterinary Sciences at the Nicolaus Copernicus University. 
Animal Rights Statement: None required.

Acknowledgements: The authors would like to thank Artur Kaczmarek from the Wonieść farm and Dmytro Radchenko from the Szołdry farm for their support and for forwarding biological material for research.

\section{References}

1. Anwar M.T., Khan A.I., Balasubramanian S., Jayaprakash R., Kannan T.A., Manokaran S., Asokan S.A., Veerapandian C.: A rare case of globosus amorphus in a goat. Can Vet J 2009, 50, $854-856$.

2. Chandramouly M., Namitha: Case series: TRAP sequence. Indian J Radiol Imaging 2009, 19, 81-83.

3. Chen H.: Atlas of genetic diagnosis and counseling. Edited by Humana Press, Totowa, New Jersey, 2006, pp. 1-6.

4. Č́tek J., Řehout V., Hájkowá J.: Congenital disorders in the cattle population of the Czech Republic. Czech J Anim Sci 2009, 54, 55-64.

5. Czarnecki C.M.: Bovine holocardius amorphus monster. Can Vet J 1976, 17, 109-110.

6. De Groot R., Van Den Wijngaard J.P., Umur A.: Modeling acardiac twin pregnancies. Ann NY Acad Sci 2007, 1101, 235-249.

7. Dennis S.M.: Holoacardius acephalic monster in sheep. Vet Rec 1965, 77, 1289-1291.

8. Dunn H.O., Lein D.H., Kenney R.M.: The cytological sex of a bovine anidian (amorphus) twin monster. Cytogenetics 1967, 6, 412-419.

9. Dun H.O., Roberts S.J.: Chromosomes studies of an ovine acephalic-acardiac monster. Cornell Vet 1972, 62, 425-431.

10. Fischer U.R., Hofmeister B.: Abnormal multiple pregnancy with septuplets in a cow. Tierärztl Praxis 2013, 41, 253-256.

11. Hanafy A., Peterson C.M.: Twin-reversed arterial perfusion (TRAP) sequence: case reports and review of literature. Aust N Z J Obstet Gynaecol 1997, 37, 187-191.
12. Hartigan P.J.: An acardius amorphus from a cow. Irish Vet J 1972, 26, 133-136.

13. Hishinuma M., Hoshi N., Takahashi Y.: Vasculature and chromosomal composition in bovine acardius amorphus. Jpn J Vet Sci 1988, 50, 1139-1141.

14. Hishinuma M., Takahashi Y., Kanagawa H.: Histological and cytological observation on a bovine acardius amorphus. Jpn J Vet Sci 1987, 49, 195-197.

15. James W.H.: A note on the epidemiology of acardiac monsters. Teratology 1978, 16, 211-216.

16. Kamimura S., Enomoto S., Goto K.: A globosus amorphous from an in vitro fertilized embryo transferred to a Japanese black cow. Theriogenology 1993, 40, 853-858.

17. Leipold H.W., Dennis S.M., Huston K.: Embryonic duplications in cattle. Cornell Vet 1972, 62, 572-580.

18. Mee J.F.: Holoacardius amorphus totalis in two Friesian cows carrying natural and induced twins. Vet Rec 1990, 127, 304-307.

19. Miyake Y., Kaneda Y., Kanagawa H.: A new type of freemartinism born co-twin with acardius amorphus. Jpn J Anim Reprod 1987, 33, 41-43.

20. Neal F.C., Wilcox C.J.: Double acardius amorphus case in a Brown Swiss cow. J Dairy Sci 1967, 50, 236

21. Nourani H., Shirazi A.A.F.: Morphological findings in bovine amorphous fetus. Iranian Vet J 2009, 4, 105-108.

22. Pourlis A.F., Amiridis G.S., Vainas E.: Two cases of bovine holocardius amorphous monsters. J Hellenic Vet Med Soc 2004, $55,120-124$

23. Singh G., Pandey A.K., Kumari S., Kumar P., Devender, Yadav V., Mishra P.K.: Amorphus globosus monster in a buffalo - a case report. Haryana Vet 2014, 53, 160-161.

24. Szczerbal I., Kociucka B., Nowacka-Woszuk J.: A high incidence of leukocyte chimerism $(60, \mathrm{XX} / 60, \mathrm{XY})$ in single born heifers culled due to underdevelopment of internal reproductive tracts. Czech J Anim Sci 2014, 59, 445-449.

25. Weber J., Rudolph N., Freick M.: Facets of clinical appearance and aetiology in an unusual bovine amorphus globosus. Anat Histol Embryol 2017, 46, 502-506.

26. Zobel R.: Amorphus globosus and freemartinism in triplets from a Holstein-Friesian cow - a case report. Theriogenology 2011, 1, 105-110. 